\title{
Application of Thiolate Self-Assembled Monolayers in Selective Alcohol Oxidation for Suppression of Pd Catalyst Deactivation
}

\author{
Pengxiao Hao ${ }^{\dagger}$, Svitlana Pylypenko ${ }^{\S}$, Daniel K. Schwartz ${ }^{\dagger}$, and J. Will Medlin ${ }^{* \dagger}$ \\ ${ }^{\dagger}$ Chem. Biol. Eng UCB 596, University of Colorado Boulder, Colorado 80309, United \\ States \\ ${ }^{\S}$ Department of Chemistry, Colorado School of Mines, Golden, Colorado 80401, United \\ States \\ *Corresponding author. Email: Will.Medlin@colorado.edu (J.W. Medlin).
}

\begin{abstract}
Rapid deactivation often reduces the effectiveness of Pt-group catalysts in the lowtemperature aerobic oxidation of alcohols. Here, we report the use of thiolate selfassembled monolayers (SAMs) as activity promoters in the liquid-phase oxidation of trans2-hexen-1-ol (HOL) under low air pressure; the oxidation rate was significantly improved, particularly at high conversion, in contrast to frequently observed activity decrease induced by SAM modification in hydrogenation reactions. Reaction studies indicated that in the regime of low air pressure, catalyst deactivation was mainly caused by the carbonaceous poisons generated from the reaction product 2-hexenal (HAL). Infrared spectroscopy revealed that HAL produced surface residues on Pd that poisoned the catalyst, hypothetically through decarbonylation and dimerization. This poisoning can be suppressed
\end{abstract}


by the SAM modifiers, in a manner that was controllable by varying thiolate surface coverage through use of either 1-adamantanethiol (AT) or 1-octadecanethiol (C18) SAMs. Keywords: alcohol oxidation, heterogeneous catalysis, palladium, deactivation, surface modification, alkanethiol, self-assembled monolayers

\section{Introduction}

The selective oxidation of alcohols is a critical component of fine chemical and pharmaceutical production [1]. Heterogeneous Pt-group catalysts, known for their ability to activate molecular oxygen and alcohols, have been widely investigated for low-temperature aerobic oxidation under environmentally benign and industry-favorable conditions [2, 3$]$. However, the commercial applicability of these catalysts is often limited by rapid deactivation. Possible deactivation routes include metal leaching and sintering [4], and "over-oxidation" of active sites when the surface coverage of oxygen is too high $[5,6]$. Under low oxygen pressure, on the other hand, surface poisoning by strongly adsorbed intermediates frequently has been reported to cause deactivation in the oxidation of primary and unsaturated alcohols $[7,8]$.

It is generally accepted that adsorbed aldehyde is produced on the catalyst surface during alcohol oxidation; the aldehyde can desorb or decompose to $\mathrm{CO}$ and carbonaceous intermediates. The presence of these surface residues can cause catalyst deactivation by blocking active sites. A number of studies have investigated aldehyde degradation during alcohol oxidation, in both ultra-high vacuum (UHV) and at the liquid-solid interface [8-11]. The classic decomposition pathways for unsaturated alcohols, as measured in UHV 
conditions on single crystal surfaces such as $\mathrm{Pd}(111)$, involve dehydrogenation to aldehydes followed primarily by decarbonylation to produce $\mathrm{CO}$ and hydrocarbon fragments; however, other pathways, including deoxygenation, have also been observed [911]. Consistent with UHV studies, aldehyde decarbonylation has been frequently reported in the liquid phase oxidation of aromatic and allylic alcohols such as benzyl, cinnamyl, and crotyl alcohols [8, 12-14], and has been attributed as a source of catalyst poisoning species.

Recent work has indicated that thiolate self-assembled monolayers (SAMs) can be used as catalyst modifiers to control the reactivity of noble metal catalysts in a number of hydrogenation reactions [15-18]. Most frequently, the improvement of selectivity to the desired products was obtained at the expense of a lowered activity, due to site blocking by the SAM modifier. In certain cases, thiolate SAMs have been shown to reduce the coverage of carbonaceous coke that blocks active sites and thus improve catalytic activity, but the detailed mechanism was still lacking $[17,18]$. One advantage of SAMs-based modifiers over other modification techniques is that their self-limiting surface coverage can be tuned in a straightforward way, by varying the tail structure [19]. For example, to create a dense SAM, the long-chain alkanethiol 1-octadecanethiol (C18) precursor can be applied, which creates a $(\sqrt{3} \times \sqrt{3})$ R30 structure on $\operatorname{Pd}(111)$ [20]; whereas a sparser SAM can be obtained by using the bulky-tailed 1-adamantanethiol (AT) [21, 22]. To date, thiolate SAMs have not been investigated as surface modifiers on Pt-group catalysts for oxidation reactions, though they have been used as capping ligands for Au nanoparticles used in oxidation [23]. 
As an important category of alcohols, a number of $\alpha, \beta$-unsaturated alcohols of different lengths have been investigated for selective oxidation, varying from allyl alcohol to 2decenol [24-26]. Here, trans-2-hexen-1-ol (HOL) was used as the probe molecule for linear unsaturated alcohols. Using AT and C18 SAM modification, we successfully limited the deactivation of a supported palladium catalyst during aerobic oxidation of HOL while maintaining the desired selectivity to the corresponding aldehyde trans-2-hexen-1-al (HAL). Kinetic studies combined with infrared spectroscopy analysis were used to investigate the role of the thiolate SAMs in controlling the formation of the surface poisoning species and preventing catalyst deactivation.

\section{Materials and Experimental Methods}

\subsection{Materials}

The 5 wt $\% \mathrm{Pd} / \mathrm{Al}_{2} \mathrm{O}_{3}$ catalyst, 1-adamantanethiol (95\%), 1-octadecanethiol (98\%), heptane (99\%), trans-2-hexen-1-ol (96\%), trans-2-hexenal (98\%), and 200-proof ethanol were purchased from Sigma-Aldrich. Catalysts received were used for reaction studies without further treatments. Zero-grade air, ultra-high purity $\mathrm{H}_{2}, \mathrm{O}_{2}, \mathrm{He}$, and $\mathrm{Ar}$ were obtained from Airgas.

\subsection{Catalyst Preparation and Characterization}

The surface area and the dispersion of commercial $\mathrm{Pd} / \mathrm{Al}_{2} \mathrm{O}_{3}$ catalyst were characterized by CO adsorption using a Micromeritics ChemiSorb 2720 system. Prior to the measurement, the catalyst was pretreated in situ by one-hour oxidation in air and three-hour reduction in $\mathrm{H}_{2}$ at $120{ }^{\circ} \mathrm{C}$, followed by one-hour purging with $\mathrm{He}$ at the same temperature. $\mathrm{CO}$ 
adsorption was performed at room temperature. The measurement gave an active surface area of $(3.0 \pm 0.5) \mathrm{m}^{2} / \mathrm{g}$ and a dispersion of $(20 \pm 4) \%$, consistent with previously reported numbers $[16,27]$. The Pd particle size was measured by TEM as $(3.3 \pm 0.5) \mathrm{nm}$ (See Fig. S1 and S2 for representative TEM images).

The thiolate SAM coated catalysts were prepared by immersing the $\mathrm{Pd} / \mathrm{Al}_{2} \mathrm{O}_{3}$ catalysts into a $1 \mathrm{mM}$ thiolate solution in ethanol. After 16 hours, the ethanol supernatant was poured off and the catalyst was immersed in pure ethanol (for AT modifier) or hexane (for C18 modifier) for three hours to remove any physisorbed thiol molecules. The supernatant was then poured off and the catalyst was dried in a vacuum desiccator for 30-60 minutes.

The freshly-prepared thiolate SAM on the catalyst was well-ordered, as indicated by diffuse reflectance Fourier transform infrared spectroscopy (DRIFTS) (Fig. S3), which showed methylene stretching frequencies consistent with organized SAMs. The surface area of the modified catalyst was measured by $\mathrm{CO}$ chemisorption after an in-situ pretreatment (threehour reduction in $20 \mathrm{sccm} \mathrm{H}_{2}$ and one-hour purging with $20 \mathrm{sccm} \mathrm{He}$ at $120^{\circ} \mathrm{C}$ ). Compared to the native catalyst, the surface area of AT- and C18-coated catalysts dropped from 3.0 $\mathrm{m}^{2} / \mathrm{g}$ to $1.7 \mathrm{~m}^{2} / \mathrm{g}$ and $0.4 \mathrm{~m}^{2} / \mathrm{g}$, respectively, suggesting that AT and $\mathrm{C} 18$ block $43 \%$ and $86 \%$ of surface sites, respectively. The sulfur content on the coated catalyst was also characterized using inductively coupled plasma optical emission spectrometry (ICP-OES). Consistent with the surface coverage given by $\mathrm{CO}$ chemisorption, the sulfur content of the C18 coating was approximately twice that of the AT coating (Table S1). The surface coverages reported here are larger than that measured by STM on single crystal surfaces 
( $\sim 18 \%$ for $\mathrm{AT}$ and $\sim 33 \%$ for $\mathrm{C} 18[20,21])$. The difference can be attributed to more corners and edges on the nanoparticle that allowed for more thiolate adsorption [28]. The size of thiol-coated catalyst was measured by TEM as $(3.4 \pm 0.7) \mathrm{nm}$, similar to that measured on the native catalyst and not affected by the thiolate modifier (Fig. S1 and S2).

For the spent catalysts, TEM, ICP-OES, and DRIFTS were used to characterize the particle size, metal and sulfur content, and the ordering of the thiolate modifier. The thiolate coating was found to remain ordered and stable after reaction according to the position of the methylene stretching features in DRIFTS (Fig. S3 and S4). However, ICP-OES suggested that both unmodified and modified palladium particles underwent leaching during the reaction (Fig. S5) without significant change of particle size (Fig. S1 and S2).

\subsection{Catalytic Reactions, Selectivity, and Rate Calculations}

The HOL oxidation reaction was run in a $100 \mathrm{~mL}$ liquid-phase semi-batch reactor at $50{ }^{\circ} \mathrm{C}$ in 40 psi air for two hours. The reaction solution included $42 \mathrm{~mL}$ heptane (solvent), $0.5 \mathrm{~mL}$ trans-2-hexen-1-ol (reactant) and $3 \mathrm{~mL}$ benzene (internal standard for gas chromatography analysis). $200 \mathrm{mg}$ catalyst $\left(\mathrm{Pd}_{\mathrm{total}}\right.$ :alcohol $\left.=1: 45 \mathrm{~mol} / \mathrm{mol}\right)$ was used for each reaction. Oxidation of cinnamyl alcohol was run in similar conditions (benzene and toluene were used as solvent and internal standard, respectively), while a higher temperature of $65{ }^{\circ} \mathrm{C}$ was applied. Eight $1 \mathrm{~mL}$ liquid samples were taken from the reactor during the reaction period. The ratio of the catalyst to the reaction solution was held constant within the reactor by simultaneously sampling liquid and catalyst, and subsequently filtering out the catalyst. 
The liquid samples were analyzed by an Agilent 5890A gas chromatography with a flame ionization detector. An Agilent HP-5 capillary was used.

The concentrations of reactants and products in the reaction solution were converted from peak areas obtained from GC analysis using corresponsive response factors, which were measured by a series of standard solutions. The concentrations of the standard solutions were comparable to reaction conditions. The selectivity and rate calculation were both based on the concentration. To avoid the ambiguity of turnover frequency (TOF) measurements, the rates here were reported as moles of reactant consumed per mole of total metal catalyst instead of per surface site, if not with particular explanations. Error bars were calculated based on repeating reactions.

\subsection{Diffuse Reflectance Fourier Transform Infrared Spectroscopy (DRIFTS)}

DRIFTS was performed using a Thermo Scientific Nicolet 6700 FT-IR. The HAL and CO adsorption analysis was performed in a closed cell attachment, and pre/post-reaction samples were analyzed with an opened sample holder. The IR spectra were taken with 2 $\mathrm{cm}^{-1}$ resolution, using 400 scans for background collection and 100 scans for sample collection.

For the HAL adsorption analysis, background spectra were obtained for the corresponding catalysts (native Pd, AT- and C18-coated Pd) prior to hexenal adsorption, thus the spectra only represented change due to HAL adsorption. In-situ pretreatment of the catalyst was performed before hexenal exposure, using Ar as the carrier gas. For uncoated samples, an 
oxidation (one hour) - reduction (three hours) procedure at $120{ }^{\circ} \mathrm{C}$ was performed, while a single three-hour-reduction at $120{ }^{\circ} \mathrm{C}$ was performed for the thiolate-coated catalysts. Background spectra were obtained in Ar flow after the samples were cooled to room temperature. Hexenal was dosed on the catalysts in Ar flow at room temperature, followed by a 20 min purging in $50 \mathrm{sccm}$ Ar flow. The spectra were taken in Ar flow immediately after the purging procedure. For the heated samples, the catalyst was elevated to the desired temperature and held for two minutes, followed by cooling to room temperature. All spectra were obtained at room temperature.

For the post-reaction samples, the catalyst was removed from the reaction solution without further treatment. The spectra were taken after drying the sample in a desiccator for 30 minutes.

\section{Results}

\subsection{Liquid-Phase Catalytic Studies}

The oxidation of HOL (Scheme 1) was performed in a semi-batch liquid phase reactor at 50 ${ }^{\circ} \mathrm{C}$ under a constant air pressure of 40 psi. The maximum rates obtained over each catalyst were reported in Table 1 . A high selectivity to HAL of approximately $90 \%$ (Table 1) was obtained on the uncoated catalyst, consistent with previous reports for similar reactions [3]. Modification of the catalyst by AT did not appreciably affect selectivity, whereas the C18 modifier lowered the selectivity to $\sim 80 \%$. Previous studies have found that dense C18 SAMs decrease the rate of double bond migration reactions less than other reactions [29], 
consistent with the dense $\mathrm{C} 18$ coating allowing more facile isomerization compared to oxidation.

Fig. 1 summarizes the conversion profile over the uncoated and modified $\mathrm{Pd} / \mathrm{Al}_{2} \mathrm{O}_{3}$ catalysts over the course of a two-hour reaction. The kinetic features were strongly influenced by thiolate modification of the surface. On the uncoated surface, a high initial rate was observed, followed by a rapid deactivation. In fact, almost half of the HOL consumed during the two-hour reaction reacted within the first five minutes. While the ATcoated catalyst exhibited a lower initial rate, presumably due to site blocking by the thiolate ligand, deactivation was not as pronounced, resulting in a higher total conversion after two hours. Similarly, the C18-coated catalyst also effectively suppressed the deactivation and increased the reaction rate over the native catalyst. Interestingly, the conversion on the C18-coated catalyst was $10 \%$ higher than that for the AT coating after two hours. This contrasted with results for hydrogenation reactions, where C18-coated catalysts showed much lower activity due to increased blocking of the surface [16-18]. The higher conversion despite increased blocking indicated that the densely packed C18 SAM suppressed catalyst deactivation more effectively.

Previous studies suggested that the deactivation of the Pd catalyst may be due to strongly adsorbed species generated by unsaturated aldehydes. Measured infrared spectra following $\mathrm{CO}$ adsorption on the catalysts (Fig. S7) suggested a significant loss of surface sites on the native catalyst after reaction, possibly due to surface poisoning by carbonaceous species. On the contrary, most of the available sites on C18-coated catalyst previous to reaction still 
remained unoccupied after reaction. We therefore hypothesized that the generation of HALderived adsorbates was responsible for the deactivation of the $\mathrm{Pd} / \mathrm{Al}_{2} \mathrm{O}_{3}$ catalysts, which could be hindered by thiol modification, more effectively by denser SAMs.

\section{Scheme 1. Reaction Pathway of HOL Oxidation.}

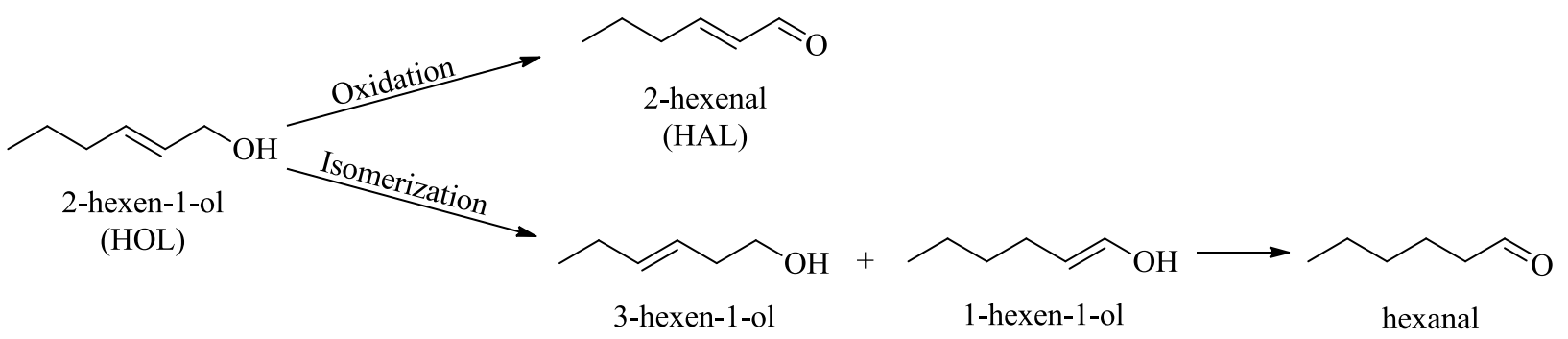

Table 1. Initial Rate and Selectivity to Trans-2-hexenal over Different Catalysts.

\begin{tabular}{|c|c|c|c|}
\hline Catalysts & $\mathrm{Pd} / \mathrm{Al}_{2} \mathrm{O}_{3}$ & $\mathrm{AT} @ \mathrm{Pd} / \mathrm{Al}_{2} \mathrm{O}_{3}$ & $\mathrm{C} 18 @ \mathrm{Pd} / \mathrm{Al}_{2} \mathrm{O}_{3}$ \\
\hline $\mathrm{TOF}^{a}\left(\mathrm{~h}^{-1}\right)$ & $(8.5 \pm 0.9) \times 10^{2}$ & $(3.8 \pm 0.4) \times 10^{2}$ & $(3.8 \pm 0.4) \times 10^{2}$ \\
\hline Selectivity to $\mathrm{HAL}^{b}(\%)$ & $89 \pm 3$ & $93 \pm 3$ & $78 \pm 1$ \\
\hline $\begin{array}{c}\text { Selectivity to isomerization } \\
\text { products }(\%)^{c}\end{array}$ & $7 \pm 3$ & $6 \pm 1$ & $18 \pm 2$ \\
\hline
\end{tabular}

(a) The maximum rates on each catalyst were obtained during the reaction coarse of first $2.5 \mathrm{~min}$.

TOF was calculated as moles of reactant consumed per mole of surface metal catalyst. A dispersion of $20 \%$ was used for both native and coated catalysts; the theoretical thiolate coverage of $18 \%$ and $33 \%$ were used for AT-coated and $\mathrm{C} 18$-coated $\mathrm{Pd} / \mathrm{Al}_{2} \mathrm{O}_{3}$, respectively. The experimental TOF for the coated catalysts should be larger than the calculated value, because the thiolate surface coverage was most possibly underestimated.

(b) The reported selectivity was calculated at $\sim 50 \%$ conversion. During the whole reaction course, the selectivity to HAL slightly increased with conversion on all surfaces with a decreasing hexanal selectivity. Selectivity to individual products as a function of conversion can be referred to Fig. S6. Reaction condition: $50{ }^{\circ} \mathrm{C}, 40 \mathrm{psi}$ air; starting reaction solution: heptane $(42 \mathrm{~mL})+$ trans-2-hexen-1ol $(0.5 \mathrm{~mL})+$ benzene $(3 \mathrm{~mL}) .200 \mathrm{mg}$ catalyst was used for each reaction. 
(c) The isomerization products include 3-hexen-1-ol and hexanal.

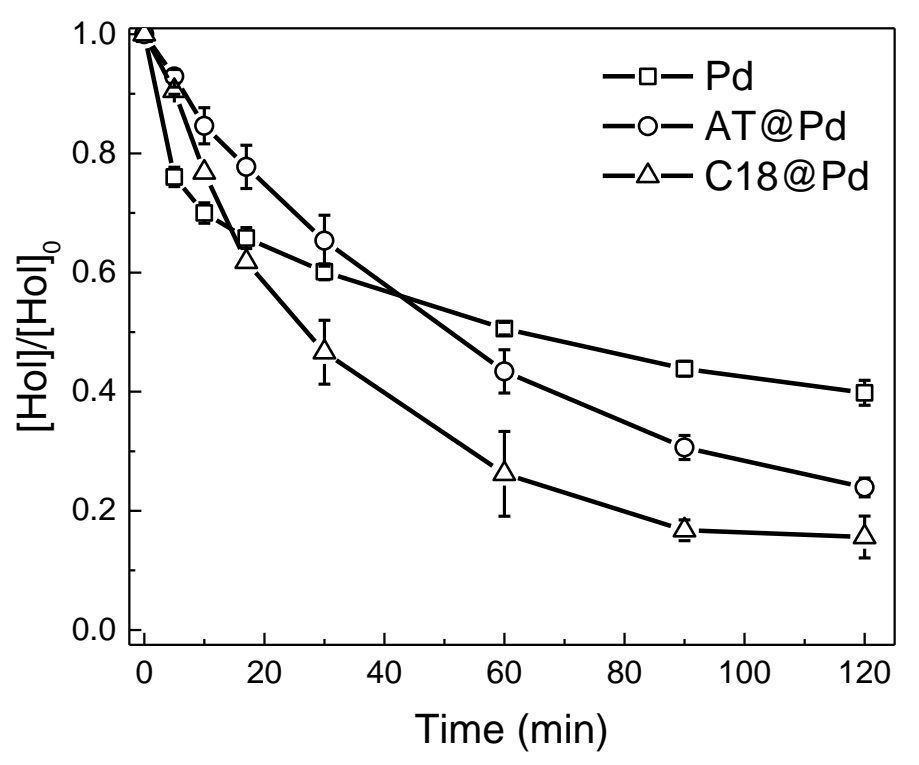

Fig. 1. Consumption of HOL on uncoated, AT-coated, and C18-coated palladium catalysts. Reactions were run at $50{ }^{\circ} \mathrm{C}$ under 40 psi air for two hours, with $\sim 0.1 \mathrm{M}$ reactant in heptane and $200 \mathrm{mg}$ catalyst.

To confirm this hypothesis, we ran reactions for which the HAL product was fed to the starting reaction solution. The amount of HAL added to the reaction solution corresponded to the amount present at $30 \%$ conversion of HOL. The activity of the catalysts was determined by the initial rate during the first two and half minutes of the reaction, as summarized in Fig. 2. In the absence of HAL, the rate was highest on the uncoated catalyst and decreased with increasing coverage of the thiolate modifier as a result of site blocking. With HAL in the feed, significantly lower activities were observed for all catalysts, but the rate on the uncoated catalyst decreased most dramatically. In fact, in the presence of HAL, the initial rate was actually improved by $60 \%$ by the AT coating and $100 \%$ by the C18 
coating, compared to the uncoated catalyst, even with blocking of active sites by the thiolate ligand. This confirmed that the thiol modification dramatically suppressed surface poisoning induced by HAL-derivatives.

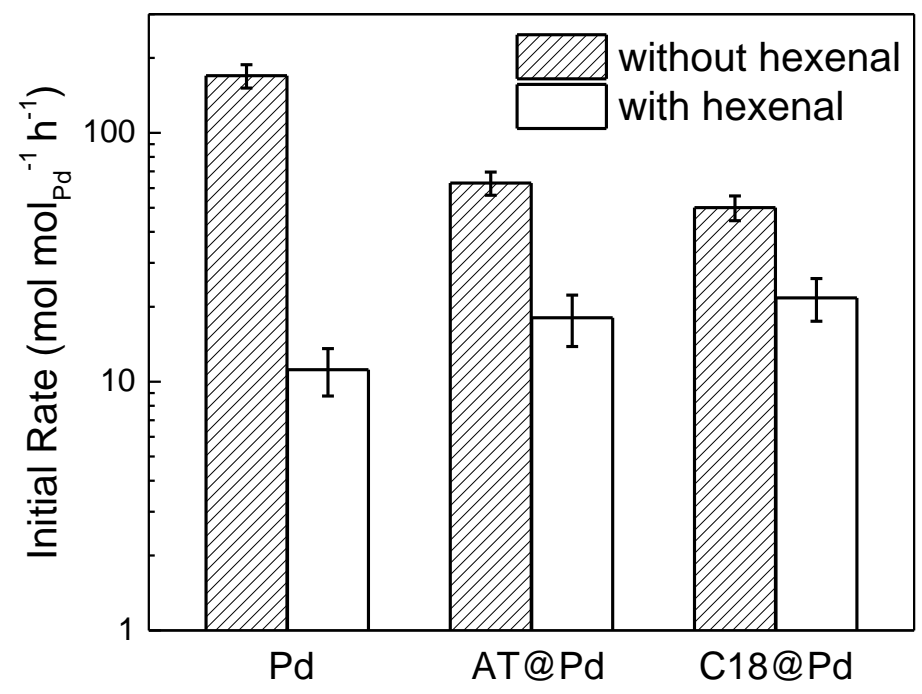

Fig. 2. Initial rates of hexenol oxidation without and with hexenal in the starting reaction mixture on uncoated, AT-coated, and $\mathrm{C} 18$-coated $\mathrm{Pd} / \mathrm{Al}_{2} \mathrm{O}_{3}$. Reactions were run at $50{ }^{\circ} \mathrm{C}$ under 40 psi air. The initial rates were obtained during the first two and half minutes of reaction. $0.15 \mathrm{~mL} \mathrm{HAL} \mathrm{(corresponding} \mathrm{to} 30 \%$ conversion) was fed to the starting reaction solution for the "with hexenal" case. As a supplement, this figure was reported in a linear scale in the supporting information (Fig. S8).

\subsection{DRIFTS of the HAL Molecules Adsorbed on the Catalyst Surfaces}

DRIFTS measurements were performed to better understand the interactions of HAL with the Pd catalysts (Fig. 3). Gas-phase HAL was exposed to the uncoated and thiolate-coated 
surfaces at room temperature, followed by incremental elevation of the temperature to 473 K. The IR spectrum of liquid-phase HAL was also shown in the figure for comparison.

Upon adsorption, the $v(\mathrm{C}=\mathrm{O})$ and $v(\mathrm{C}=\mathrm{C})$ stretching modes of HAL were red-shifted on all surfaces from $1692 \mathrm{~cm}^{-1}$ to $1670 \mathrm{~cm}^{-1}$, and from $1640 \mathrm{~cm}^{-1}$ to $1624 \mathrm{~cm}^{-1}$, respectively. This was consistent with previous reports of adsorbed allylic aldehydes acrolein and crotonaldehyde on $\mathrm{Pt}$ [30-32], where $\mathrm{C}=\mathrm{O}$ and $\mathrm{C}=\mathrm{C}$ bonds interacted with the palladium surface. With increased temperature, a significant attenuation of the $v(\mathrm{C}=\mathrm{O})$ peak occurred on all three surfaces, indicating the consumption of the $\mathrm{C}=\mathrm{O}$ group through reaction (i.e. decarbonylation) or desorption of HAL. Different spectral features were observed on the three surfaces in the regions of $1500-1600 \mathrm{~cm}^{-1}$ and $1750-2000 \mathrm{~cm}^{-1}$, suggesting that the chemistry of HAL on the Pd surface was altered by the thiolate modifier.

Strong peaks at 1593 and $1566 \mathrm{~cm}^{-1}\left(\mathrm{CO}_{2}^{-}\right.$asymmetric stretching region [33]) were observed upon HAL adsorption on the uncoated surface and gradually increased in magnitude with increasing temperature. Because similar peaks were previously assigned to benzoate species produced from benzyl alcohol adsorbed on $\mathrm{Pd} / \mathrm{Al}_{2} \mathrm{O}_{3}$ under $\mathrm{Ar}$ [8], we attribute these features to HAL-derived carboxylate species. The carboxylates were presumably formed from HAL dimerization/oligomerization rather than oxidation, as abundant surface oxygen was unlikely to be available for aldehyde oxidation under the anaerobic conditions employed here. Similar oligomerization reactions have been suggested for aldehydes on metal surfaces [34, 35], and have been attributed to causing surface poisoning during alcohol oxidations on Pd [36, 37]. In the presence of either AT or C18 
SAMs, however, the peaks at 1593 and $1566 \mathrm{~cm}^{-1}$ were not observed, suggesting that the surface coatings suppressed the adsorption of adjacent HAL molecules and/or large dimer species during dimerization. We attribute the decrease in the extent of deactivation on the SAM-coated catalysts to this suppression of adsorbed dimers.

Based on the DRIFTS results, the most abundant surface species formed on the AT- and C18-coated surfaces were also distinct, however. The AT-coated surface exhibited the appearance of surface $\mathrm{CO}$ at $1835 \mathrm{~cm}^{-1}$ at room temperature. In contrast, surface $\mathrm{CO}$ was barely detected at room temperature on either the uncoated or the C18-coated surfaces. Because decarbonylation of unsaturated aldehydes is known to occur below room temperature on $\mathrm{Pd}$ surfaces $[9,10,38]$, we attributed the absence of $\mathrm{CO}$ to the high coverage of hexenal-derived surface intermediates or $\mathrm{C} 18$-thiols rather than a barrier intrinsic to the Pd surface. Suppression of decarbonylation on Pd has also been reported by Ferri et al., using Bi as modifier to block Pd surface sites [39]. Similarly, according to Pang et al., the C18 coating can more severely limit the threefold sites on palladium than the ATcoating [22]. The decrease of threefold sites may prevent the flat-lying adsorption of the aldehyde through $\mathrm{C}=\mathrm{C}$ and $\mathrm{C}=\mathrm{O}$ bonds, which was reported as the primary adsorption geometry on $\operatorname{Pd}(111)$ surface [40]. Decarbonylation was thus unfavorable, as it was hypothesized to require the interaction between $\mathrm{C}=\mathrm{O}$ bond and metal surface [30]. Thus, in addition to blocking formation of dimers, the denser C18 monolayers also appeared to suppress decarbonylation. We speculated that the enhanced effectiveness of the C18 coating compared to AT was related to the inhibition of both of these side reactions. 
While decarbonylation was hindered at low temperature on both uncoated and C18-coated surfaces, it could be activated at higher temperatures, as indicated by the detection of $\mathrm{CO}$ in temperature-programmed desorption experiments (Fig. S9). However, little or no CO signal was observed on the surface (Fig. 3), indicating that $\mathrm{CO}$ desorbed as soon as it was produced.

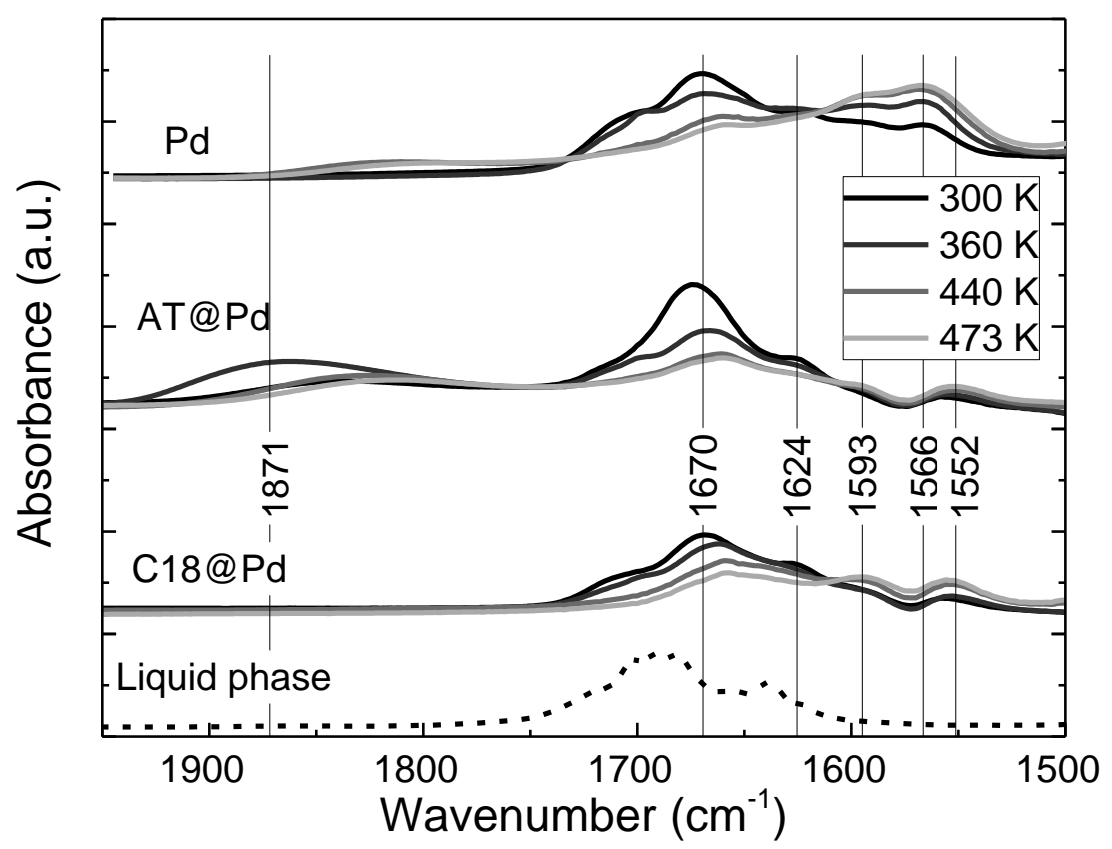

Fig. 3. DRIFTS of hexenal adsorption on uncoated, AT-coated, and C18-coated $\mathrm{Pd} / \mathrm{Al}_{2} \mathrm{O}_{3}$.

\subsection{Reusability of the SAM-Coated Palladium Catalysts}

To test the stability of the thiolate modifier on the palladium catalysts, recycling studies were performed under the same reaction conditions. The catalyst was recovered following each reaction and re-used without further treatment. As shown in Fig. 4, the activity of the uncoated catalyst dropped markedly after the first run, and modest additional deactivation occurred with further reactions. For the AT- and C18-coated catalyst, however, the activity 
remained virtually unchanged after three runs. Metal leaching occurred on all native and modified catalysts during the reaction, as suggested by ICP-OES analysis (Fig. S5), which could not be observed from Fig. 4 because the rate was calculated on a mole of Pd basis. In contrast to the instability of Pd, elemental and spectroscopic analysis suggested that the thiolate modifier remained stable, showing no significant desorption nor disordering after exposure to reaction conditions (Fig. S3 and S4). X-ray photoelectron spectroscopy (XPS) analysis indicated that the thiolate coating was not oxidized to form sulfates during the reaction (Fig. S11). On the contrary, they were reduced, possibly by the hydrogen generated from HOL or HAL adsorption. The recycling studies suggested again that the AT and $\mathrm{C} 18$ modifiers were able to hinder poisoning and remain stable on the Pd surface for at least three successive reaction runs. On the other hand, the uncoated catalyst was strongly poisoned by exposure to reaction conditions. Thus, while both the uncoated and coated catalysts exhibited a layer of strongly adsorbed spectator species shortly after reaction initiation, in the case of the thiol coating the organized SAM layer fostered greater reactivity than the layer of hexenal-derived intermediates produced from reaction on the uncoated catalyst. 


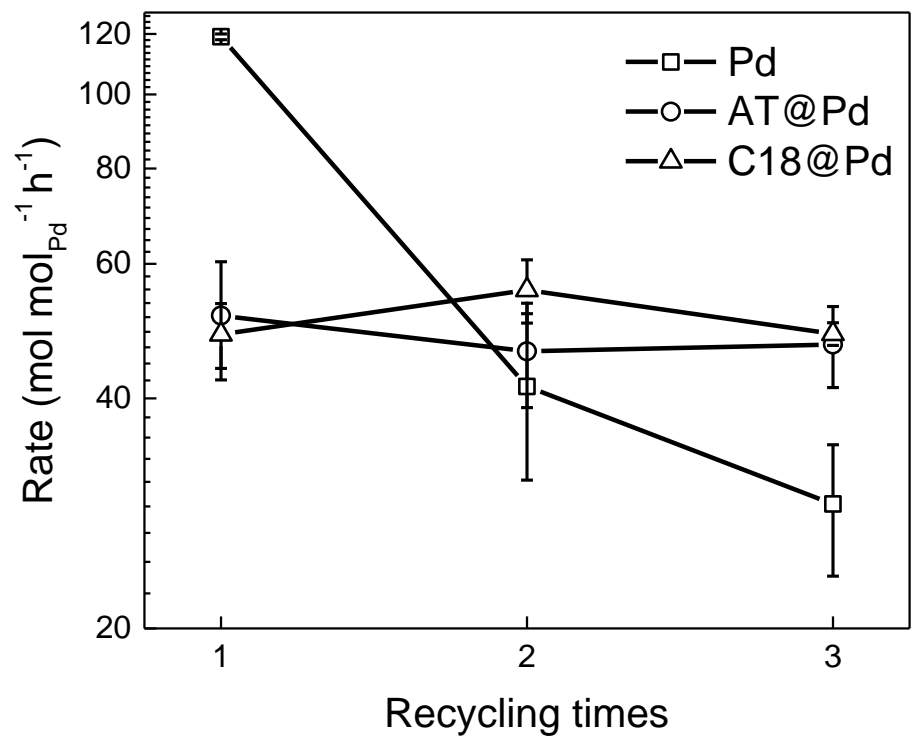

Fig. 4. Rates of HOL oxidation on different palladium catalysts for recycling studies.

Average rates over the first five minutes of reaction were measured to represent the activity of the catalysts. As a supplement, this figure was reported in a linear scale in the supporting information (Fig. S10).

\section{Discussion}

As discussed above, the poisoning species can be attributed to formation of HAL dimers or oligomers and to decarbonylation to $\mathrm{CO}$ and carbonaceous residue. While $\mathrm{CO}$ can be readily removed by reaction with surface oxygen to produce $\mathrm{CO}_{2}$ under oxidation conditions, the easy removal of hydrocarbon fragments is not expected $[4,13]$. The absence of surface $\mathrm{CO}$ has been confirmed by the polarization-modulation infrared reflectionabsorption spectroscopy (PM-IRRAS) study of the liquid phase oxidation of benzyl alcohol at $50{ }^{\circ} \mathrm{C}$ [12]. Whereas accumulation of $\mathrm{CO}$ on the Pd surface was detected in the absence of $\mathrm{O}_{2}$, no surface $\mathrm{CO}$ was observed under aerobic conditions. Thus under the reaction 
conditions employed here, hydrocarbon residue instead of $\mathrm{CO}$ on the surface is proposed to be the major cause of catalyst deactivation. Similar observations reported by Pastor et al. suggested that short carbonaceous fragments such as $\mathrm{CH}_{3} \mathrm{CH}_{2} \mathrm{CO}_{\mathrm{ad}}, \mathrm{CH}_{3} \mathrm{CH}_{2 \mathrm{ad}}$, and $\mathrm{CH}_{3} \mathrm{CH}_{2} \mathrm{CH}_{2 \mathrm{ad}}$, were the strongly adsorbed species on Pt during electrooxidation of 1propanol [41]. Moreover, Burgener et al. proposed that citral underwent dimerization and oligomerization on the Pd surface, resulting in irreversible catalyst deactivation that could not be caused by decarbonylation alone [42]. These studies support our hypothesis for the promoting effect of AT and C18; while the uncoated surface suffers from the poisoning by HAL-dimer, the AT-coated surface is mainly poisoned by the short carbonaceous fragments. The C18-coated surface, on the other hand, resists the adsorption of both species more effectively and exhibits a better performance.

As mentioned above, bismuth has been previously used to suppress deactivation of Ptgroup catalysts during alcohol oxidation. In addition to $\mathrm{Bi}$, other inorganic promoters, such as lead, tin, and gold, have also been applied as catalyst promoters [5, 43-45]. These promoters have sometimes been reported to decrease the extent of catalyst deactivation by promoting desorption of aldehydes or suppressing the decarbonylation pathway. Besides the purported site blocking effect, as discussed for $\mathrm{Bi}$, another frequently reported mechanism involves the dilution effect of catalytic sites, also known as the "ensemble effect" [46]. In this model, a promoter geometrically isolates individual active sites to prevent the formation and adsorption of the surface-poisoning species that require large regions of continuous surface sites $[13,47,48]$. In addition, promoters such as $\mathrm{Bi}$ and $\mathrm{Sn}$ have also been suggested to enhance desorption of aldehydes by altering the electronic 
structure of the catalysts [49-51], or by forming promoter-adsorbate complexes [52, 53]. The ambiguity of the promoter effect is partially due to the complex nature of the bimetallic surface and the difficulty in controllably manipulating the surface structure. In this study, the thiolate modifiers are proposed to limit deactivation in a similar manner to metallic promoters such as $\mathrm{Bi}$, i.e. by blocking active sites to prevent side reactions that form strongly bound species. The adsorption sites and the coverage of the modifier influences the activity of dimerization and decarbonylation in the oxidation of HOL. We did not detect a change in the electronic state of Pd due to thiolate modification in XPS (Fig. S13), but a subtle influence of thiolates on the electronic structure of the active site cannot be ruled out, and in fact has been proposed to be important in other reactions [16]. While the deposition of bimetallic modifiers often requires careful control and characterization, thiolate modification is self-limiting and can be conveniently controlled by varying the steric bulk of the tail group.

The tuning of the thiolate coverage to achieve selectivity control has been used previously for hydrogenation reactions [22, 27]. Pang et al. demonstrated that active sites can be selectively blocked by varying the tail of thiolate modifiers to facilitate either decarbonylation or hydrogenation of furfural on supported Pd catalysts. Here, we similarly observe that under significantly different reaction conditions (oxygen-containing environment, liquid-phase reaction mixture) thiolates also have a significant effect on selectivity. However, for the current study, the thiolate monolayers appear to selectively suppress dimerization side reactions leading to surface poisons. 
Previous studies have proposed that oxidation of palladium catalysts can result in lessactive oxidized Pd species [39]. More recent studies, however, have indicated that oxidized Pd sites are actually the active site for the reaction [3, 14]. In any case, investigations of the performance of thiolate coatings as a function of oxygen pressure are of interest, in part because degradation of the catalyst coatings, presumably via oxidation of the surface sulfur, has also been observed after exposing thiolate-coated catalysts to air [20, 54]. In preliminary investigations, we observed a lower reaction rate for the uncoated catalyst at an air pressure of $60 \mathrm{psi}$ than $40 \mathrm{psi}$; in contrast, the rate on the AT-coated catalyst increased over the same pressure range (Fig. S12). While such behavior might suggest that the thiolate coating improves resistance to "over-oxidation", the prior work discussed above casts doubt on such a conclusion. However, it seems clear that thiolate coatings changed the surface interaction with both 2-hexenal and oxygen, in the latter case promoting activity at higher pressure. XPS studies conducted on pre- and post-reaction catalysts confirmed no significant oxidation of either the Pd or the thiolate coating during the reaction (Fig. S11 and Fig. S13). The absence of the increase in the features associated with sulfur oxidation in the XPS spectra is consistent with the reusability studies, which indicate stable performance of the catalysts upon recycling. The resistance to oxidation is probably due to the relatively low oxygen pressure that allows oxygen to only remove the surface species (e.g., $\mathrm{CO}$ and hydrogen) without oxidation of Pd or sulfur. This suggests that the thiolate modifier is stable and potentially applicable in mild oxidative conditions. However, its stability and the ability to prevent Pd over-oxidation under high oxygen pressure need to be further studied. 
This thiolate modification may be extendable to other unsaturated alcohols. As a preliminary test, we evaluated the uncoated and C18-coated Pd catalysts for the oxidation of cinnamyl alcohol to cinnamaldehyde. The C18 coating again lowered the initial rate of reaction in aldehyde-free conditions (Table 2), but exhibited a higher initial rate in the presence of cinnamaldehyde. The magnitude of the C18 effects was much lower than that from HOL, indicating that the observed influence of the SAM coating may be sensitive to the alcohol oxidation chemistry, hypothetically due to various kinetics of aldehyde decomposition/dimerization reactions that occur from different precursors.

Table 2. Initial Rates of Cinnamyl Alcohol Oxidation.

\begin{tabular}{|c|c|c|}
\hline Rate $^{a}\left(\mathrm{~mol} \mathrm{~mol}_{\mathrm{Pd}}{ }^{-1} \mathrm{~h}^{-1}\right)$ & $\mathrm{Pd} / \mathrm{Al}_{2} \mathrm{O}_{3}$ & $\mathrm{C} 18 @ \mathrm{Pd} / \mathrm{Al}_{2} \mathrm{O}_{3}$ \\
\hline Without cinnamaldehyde feeding & $(1.9 \pm 0.1) \times 10^{1}$ & $(1.5 \pm 0.2) \times 10^{1}$ \\
\hline With cinnamaldehyde feeding & $4.9 \pm 0.1$ & $6.4 \pm 0.9$ \\
\hline
\end{tabular}

(a) Reactions were run at $65{ }^{\circ} \mathrm{C}$ under 40 psi air. The initial rates were obtained over $0-10 \%$ of the conversion range. $0.19 \mathrm{~mL}$ cinnamaldehyde (corresponding to $\sim 30 \%$ conversion) was fed to the starting reaction solution for the "with cinnamaldehyde feeding" case.

\section{Conclusions}

Here, we demonstrate that thiolate SAMs can be applied as promoters on the supported palladium catalysts in the liquid-phase HOL oxidation. The reaction product HAL formed surface residues on native $\mathrm{Pd} / \mathrm{Al}_{2} \mathrm{O}_{3}$ that poison the catalyst. By thiolate modification, $\mathrm{HAL}$ poisoning was limited, hypothetically due to isolation of active sites. On the AT-coated surface, decarbonylation was the major side reaction of HAL, forming smaller carbonaceous fragments that blocked fewer active sites and were more easily removed from the surface. The C18-coated surface hindered decarbonylation and the production of a HAL-derived surface poison attributed to a surfaces dimer, and exhibited the highest 
activity. Therefore, the thiolate modifier was able to improve the catalytic activity and help prevent deactivation by suppressing the side reactions of HAL and thus the formation of poisoning species. Compared to conventional metallic promoters, the thiolate modifiers provide a more straightforward platform for a controlled design of the near-surface environment. This ability makes it an attractive potential modifier of the Pt-group catalysts for low-temperature aerobic oxidation of alcohols.

\section{Acknowledgements}

This research was supported by the Department of Energy, Office of Science, Basic Energy Sciences Program, Chemical Sciences, Geosciences, and Biosciences Division, under Grant No. DE-SC0005239. The authors would also like to acknowledge Dr. Frederick G. Luiszer for help with ICP-OES analysis, and Lucas Ellis and Hans Funke for the development of the TPD unit. 


\section{References}

[1] S.E. Davis, M.S. Ide, R.J. Davis, Selective oxidation of alcohols and aldehydes over supported metal nanoparticles, Green Chem., 15 (2013) 17-45. DOI: 10.1039/c2gc36441g [2] T. Mallat, A. Baiker, Oxidation of alcohols with molecular oxygen on solid catalysts, Chem. Rev., 104 (2004) 3037-3058. DOI: 10.1021/cr0200116

[3] S.F. Hackett, R.M. Brydson, M.H. Gass, I. Harvey, A.D. Newman, K. Wilson, A.F. Lee, High-activity, single-site mesoporous $\mathrm{Pd} / \mathrm{Al} 2 \mathrm{O} 3$ catalysts for selective aerobic oxidation of allylic alcohols, Angew. Chem. Int. Ed. Engl., 46 (2007) 8593-8596. DOI: 10.1002/anie.200702534

[4] M.S. Ide, D.D. Falcone, R.J. Davis, On the deactivation of supported platinum catalysts for selective oxidation of alcohols, J. Catal., 311 (2014) 295-305. DOI: 10.1016/j.jcat.2013.12.002

[5] C. Mondelli, J.D. Grunwaldt, D. Ferri, A. Baiker, Role of Bi promotion and solvent in platinum-catalyzed alcohol oxidation probed by in situ X-ray absorption and ATR-IR spectroscopy, Phys. Chem. Chem. Phys., 12 (2010) 5307-5316. DOI: 10.1039/b926833b

[6] C. Keresszegi, T. Burgi, T. Mallat, A. Baiker, On the role of oxygen in the liquid-phase aerobic oxidation of alcohols on palladium, J. Catal., 211 (2002) 244-251. DOI: 10.1006/jcat.2002.3723

[7] M. Besson, P. Gallezot, Selective oxidation of alcohols and aldehydes on metal catalysts, Catal. Today, 57 (2000) 127-141. DOI: 10.1016/S0920-5861(99)00315-6

[8] C. Keresszegi, D. Ferri, T. Mallat, A. Baiker, On the role of CO formation during the aerobic oxidation of alcohols on $\mathrm{Pd} / \mathrm{Al} 2 \mathrm{O} 3$ : an, in situ attenuated total reflection infrared study, J. Catal., 234 (2005) 64-75. DOI: 10.1016/j.jcat.2005.05.019

[9] S.H. Pang, A.M. Roman, J.W. Medlin, Adsorption Orientation-Induced Selectivity Control of Reactions of Benzyl Alcohol on Pd(111), J. Phys. Chem. C, 116 (2012) 1365413660. DOI: $10.1021 /$ jp303147c

[10] R.M. Williams, J.W. Medlin, Benzyl Alcohol Oxidation on Pd(111): Aromatic Binding Effects on Alcohol Reactivity, Langmuir, 30 (2014) 4642-4653. DOI: 10.1021/la5001304

[11] A.F. Lee, Z. Chang, P. Ellis, S.F.J. Hackett, K. Wilson, Selective oxidation of crotyl alcohol over pd(111), J. Phys. Chem. C, 111 (2007) 18844-18847. DOI: 10.1021/jp709944c [12] D.M. Meier, A. Urakawa, A. Baiker, In Situ PM-IRRAS Study of Liquid-Phase Benzyl Alcohol Oxidation on Palladium, J. Phys. Chem. C, 113 (2009) 21849-21855. DOI: 10.1021/jp908071m

[13] C. Keresszegi, T. Mallat, J.D. Grunwaldt, A. Baiker, A simple discrimination of the promoter effect in alcohol oxidation and dehydrogenation over platinum and palladium, J. Catal., 225 (2004) 138-146. DOI: 10.1016/j.jcat.2004.04.002

[14] A.F. Lee, C.V. Ellis, J.N. Naughton, M.A. Newton, C.M.A. Parlett, K. Wilson, Reaction-Driven Surface Restructuring and Selectivity Control in Allylic Alcohol Catalytic Aerobic Oxidation over Pd, J. Am. Chem. Soc., 133 (2011) 5724-5727. DOI: 10.1021/ja200684f

[15] K.R. Kahsar, D.K. Schwartz, J.W. Medlin, Control of Metal Catalyst Selectivity through Specific Noncovalent Molecular Interactions, J. Am. Chem. Soc., 136 (2013) 520526. DOI: $10.1021 / \mathrm{ja} 411973 \mathrm{p}$ 
[16] S.T. Marshall, M. O'Brien, B. Oetter, A. Corpuz, R.M. Richards, D.K. Schwartz, J.W. Medlin, Controlled selectivity for palladium catalysts using self-assembled monolayers, Nature Materials, 9 (2010) 853-858. DOI: 10.1038/nmat2849

[17] C.A. Schoenbaum, D.K. Schwartz, J.W. Medlin, Controlling surface crowding on a Pd catalyst with thiolate self-assembled monolayers, J. Catal., 303 (2013) 92-99. DOI: 10.1016/j.jcat.2013.03.012

[18] C.H. Lien, J.W. Medlin, Promotion of Activity and Selectivity by Alkanethiol Mono layers for Pd-Catalyzed Benzyl Alcohol Hydrodeoxygenation, J. Phys. Chem. C, 118 (2014) 23783-23789. DOI: 10.1021/jp507114g

[19] C.A. Schoenbaum, D.K. Schwartz, J.W. Medlin, Controlling the surface environment of heterogeneous catalysts using self-assembled monolayers, Acc. Chem. Res., 47 (2014) 1438-1445. DOI: 10.1021/ar500029y

[20] J.C. Love, D.B. Wolfe, R. Haasch, M.L. Chabinyc, K.E. Paul, G.M. Whitesides, R.G. Nuzzo, Formation and structure of self-assembled monolayers of alkanethiolates on palladium, J. Am. Chem. Soc., 125 (2003) 2597-2609. DOI: 10.1021/ja028692+

[21] A.A. Dameron, L.F. Charles, P.S. Weiss, Structures and displacement of 1adamantanethiol self-assembled monolayers on $\mathrm{Au}\{111\}$, J. Am. Chem. Soc., 127 (2005) 8697-8704. DOI: 10.1021/ja042621o

[22] S.H. Pang, C.A. Schoenbaum, D.K. Schwartz, J.W. Medlin, Directing reaction pathways by catalyst active-site selection using self- assembled monolayers, Nature Communications, 4 (2013) 6. DOI: 10.1038/ncomms3448

[23] Y. Zhu, H. Qian, M. Zhu, R. Jin, Thiolate-protected Au(n) nanoclusters as catalysts for selective oxidation and hydrogenation processes, Adv. Mater., 22 (2010) 1915-1920. DOI: 10.1002/adma.200903934

[24] Y. Kon, Y. Usui, K. Sato, Oxidation of allylic alcohols to alpha, beta-unsaturated carbonyl compounds with aqueous hydrogen peroxide under organic solvent-free conditions, Chem. Commun., (2007) 4399-4400. DOI: 10.1039/B708612A

[25] A. Maclennan, A. Banerjee, R.W.J. Scott, Aerobic oxidation of alpha,beta-unsaturated alcohols using sequentially-grown AuPd nanoparticles in water and tetraalkylphosphonium ionic liquids, Catal. Today, 207 (2013) 170-179. DOI: 10.1016/j.cattod.2012.04.053

[26] L. Prati, A. Villa, C. Campione, P. Spontoni, Effect of gold addition on Pt and Pd catalysts in liquid phase oxidations, Top. Catal., 44 (2007) 319-324. DOI: 10.1007/s11244007-0305-9

[27] S.H. Pang, C.A. Schoenbaum, D.K. Schwartz, J.W. Medlin, Effects of Thiol Modifiers on the Kinetics of Furfural Hydrogenation over Pd Catalysts, ACS Catal., 4 (2014) 31233131. DOI: $10.1021 / \mathrm{csSOO598y}$

[28] M.J. Hostetler, J.E. Wingate, C.-J. Zhong, J.E. Harris, R.W. Vachet, M.R. Clark, J.D. Londono, S.J. Green, J.J. Stokes, G.D. Wignall, G.L. Glish, M.D. Porter, N.D. Evans, R.W. Murray, Alkanethiolate Gold Cluster Molecules with Core Diameters from 1.5 to $5.2 \mathrm{~nm}$ : Core and Monolayer Properties as a Function of Core Size, Langmuir, 14 (1998) 17-30. DOI: $10.1021 / \mathrm{la970588w}$

[29] S.H. Pang, C.-H. Lien, J.W. Medlin, Control of surface alkyl catalysis with thiolate monolayers, Catal. Sci. Technol., 6 (2016) 2413-2418. DOI: 10.1039/c5cy01831e

[30] J.C. de Jesús, F. Zaera, Adsorption and thermal chemistry of acrolein and crotonaldehyde on Pt(111) surfaces, Surf. Sci., 430 (1999) 99-115. DOI: 10.1016/s00396028(99)00406-9 
[31] J. Haubrich, D. Loffreda, F. Delbecq, P. Sautet, Y. Jugnet, C. Becker, K. Wandelt, Adsorption and Vibrations of alpha,beta-Unsaturated Aldehydes on $\mathrm{Pt}(111)$ and $\mathrm{Pt}-\mathrm{Sn}$ Alloy (111) Surfaces. 3. Adsorption Energy vs Adsorption Strength, J. Phys. Chem. C, 114 (2010) 1073-1084. DOI: 10.1021/jp908353p

[32] J. Haubrich, D. Loffreda, F. Delbecq, P. Sautet, A. Krupski, C. Becker, K. Wandeltt, Adsorption of alpha,beta-Unsaturated Aldehydes on $\mathrm{Pt}(111)$ and $\mathrm{Pt}-\mathrm{Sn}$ Alloys: II. Crotonaldehyde, J. Phys. Chem. C, 113 (2009) 13947-13967. DOI: 10.1021/jp903473m [33] D.A. Long, Infrared and Raman Characteristic Group Frequencies: Tables and Charts, in: Journal of Raman Spectroscopy, 2004, p. 18.

[34] M.A. Henderson, G.E. Mitchell, J.M. White, The decomposition of formaldehyde on Pt(111): A TPD and hreels study, Surf. Sci., 188 (1987) 206-218. DOI: 10.1016/s00396028(87)80152-8

[35] M. Pan, A.J. Brush, G.B. Dong, C.B. Mullins, Tunable Ether Production via Coupling of Aldehydes or Aldehyde/Alcohol over Hydrogen-Modified Gold Catalysts at Low Ternperatures, Journal of Physical Chemistry Letters, 3 (2012) 2512-2516. DOI: $10.1021 / \mathrm{jz} 301105 \mathrm{e}$

[36] C. Keresszegi, On the mechanism of the aerobic oxidation and dehydrogenation of alcohols on palladium and platinum, Eidgenössische Technische Hochschule ETH Zürich, (2005). DOI: http://dx.doi.org/10.3929/ethz-a-004998066

[37] T. Mallat, A. Baiker, LIQUID-PHASE OXIDATION OF 1-METHOXY-2PROPANOL WITH AIR .1. LEAD AND BISMUTH PROMOTION AND DEACTIVATION OF PALLADIUM CATALYSTS, Applied Catalysis, 79 (1991) 41-58. DOI: $10.1016 / 0926-860 x(91) 85005-\mathrm{i}$

[38] S.T. Marshall, C.M. Horiuchi, W.Y. Zhang, J.W. Medlin, Common Decomposition Pathways of 1-Epoxy-3-butene and 2-Butenal on Pd(111), J. Phys. Chem. C, 112 (2008) 20406-20412. DOI: 10.1021/jp804936y

[39] D. Ferri, A. Baiker, Advances in Infrared Spectroscopy of Catalytic Solid-Liquid Interfaces: The Case of Selective Alcohol Oxidation, Top. Catal., 52 (2009) 1323-1333. DOI: $10.1007 / \mathrm{s} 11244-009-9310-5$

[40] F. Delbecq, P. Sautet, COMPETITIVE C=C AND C=O ADSORPTION OF ALPHABETA-UNSATURATED ALDEHYDES ON PT AND PD SURFACES IN RELATION WITH THE SELECTIVITY OF HYDROGENATION REACTIONS - A THEORETICAL APPROACH, J. Catal., 152 (1995) 217-236. DOI: 10.1006/jcat.1995.1077

[41] E. Pastor, S. Wasmus, T. Iwasita, M.C. Arevalo, S. Gonzalez, A.J. Arvia, Spectroscopic Investigations of C-3 Primary Alcohols on Platinum-Electrodes in AcidSolutions .1. N-Propanol, J. Electroanal. Chem., 350 (1993) 97-116. DOI: 10.1016/00220728(93)80199-R

[42] M. Burgener, R. Wirz, T. Mallat, A. Baiker, Nature of catalyst deactivation during citral hydrogenation: a catalytic and ATR-IR study, J. Catal., 228 (2004) 152-161. DOI: 10.1016/j.jcat.2004.09.006

[43] F. Alardin, B. Delmon, P. Ruiz, M. Devillers, Stability of bimetallic Bi-Pd and Pb-Pd carbon-supported catalysts during their use in glyoxal oxidation, Catal. Today, 61 (2000) 255-262. DOI: 10.1016/S0920-5861(00)00377-1

[44] T. Balcha, J.R. Strobl, C. Fowler, P. Dash, R.W.J. Scott, Selective Aerobic Oxidation of Crotyl Alcohol Using AuPd Core-Shell Nanoparticles, ACS Catal., 1 (2011) 425-436. DOI: $10.1021 / \operatorname{cs} 200040 \mathrm{a}$ 
[45] N. Dimitratos, A. Villa, D. Wang, F. Porta, D.S. Su, L. Prati, Pd and Pt catalysts modified by alloying with $\mathrm{Au}$ in the selective oxidation of alcohols, J. Catal., 244 (2006) 113-121. DOI: 10.1016/j.jcat.2006.08.019

[46] D.M. Alonso, S.G. Wettstein, J.A. Dumesic, Bimetallic catalysts for upgrading of biomass to fuels and chemicals, Chem. Soc. Rev., 41 (2012) 8075-8098. DOI: $10.1039 / \mathrm{c} 2 \mathrm{cs} 35188 \mathrm{a}$

[47] L. Demarconnay, S. Brimaud, C. Coutanceau, J.M. Leger, Ethylene glycol electrooxidation in alkaline medium at multi-metallic Pt based catalysts, J. Electroanal. Chem., 601 (2007) 169-180. DOI: 10.1016/j.jelechem.2006.11.006

[48] T. Mallat, Z. Bodnar, P. Hug, A. Baiker, Selective Oxidation of Cinnamyl Alcohol to Cinnamaldehyde with Air over Bi-Pt/Alumina Catalysts, J. Catal., 153 (1995) 131-143. DOI: $10.1006 /$ jcat.1995.1115

[49] S. Karski, I. Witonska, Bismuth as an additive modifying the selectivity of palladium catalysts, J. Mol. Catal. A: Chem., 191 (2003) 87-92. DOI: 10.1016/S1381-1169(02)00359$\mathrm{X}$

[50] A. Villa, D. Wang, N. Dimitratos, D.S. Su, V. Trevisan, L. Prati, Pd on carbon nanotubes for liquid phase alcohol oxidation, Catal. Today, 150 (2010) 8-15. DOI: 10.1016/j.cattod.2009.06.009

[51] D.I. Enache, J.K. Edwards, P. Landon, B. Solsona-Espriu, A.F. Carley, A.A. Herzing, M. Watanabe, C.J. Kiely, D.W. Knight, G.J. Hutchings, Solvent-free oxidation of primary alcohols to aldehydes using Au-Pd/TiO2 catalysts, Science, 311 (2006) 362-365. DOI: 10.1126/science. 1120560

[52] H.H.C.M. Pinxt, B.F.M. Kuster, G.B. Marin, Promoter effects in the Pt-catalysed oxidation of propylene glycol, Appl. Catal. A - Gen., 191 (2000) 45-54. DOI: 10.1016/S0926-860x(99)00304-X

[53] M. Wenkin, P. Ruiz, B. Delmon, M. Devillers, The role of bismuth as promoter in PdBi catalysts for the selective oxidation of glucose to gluconate, J. Mol. Catal. A: Chem., 180 (2002) 141-159. DOI: 10.1016/S1381-1169(01)00421-6

[54] K.R. Kahsar, D.K. Schwartz, J.W. Medlin, Stability of self-assembled monolayer coated Pt/Al2O3 catalysts for liquid phase hydrogenation, J. Mol. Catal. A: Chem., 396 (2015) 188-195. DOI: 10.1016/j.molcata.2014.10.004 


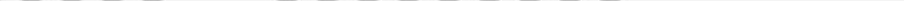

